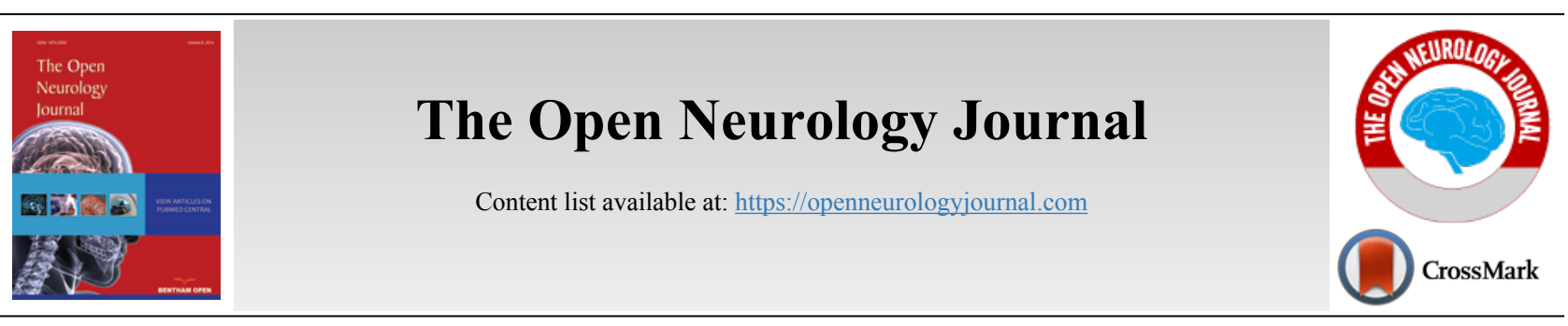

RESEARCH ARTICLE

\title{
Infantile Hydrocephalus: Health-Related Quality of Life Outcome following Ventriculoperitoneal Shunt
}

\author{
Haytham Eloqayli ${ }^{1,2, *}$ and Ali Alyousef ${ }^{3}$ \\ ${ }^{\prime}$ Department of Neurosurgery, Faculty of Medicine, Jordan University of Science and Technology, Irbid, Jordan \\ ${ }^{2}$ Emirate Specialty Hospital, Dubai Healthcare City, Dubai, UAE \\ ${ }^{3}$ Computer and Information Technology College, Jerash University, Irbid, Jordan
}

\begin{abstract}
:
Aims:

To investigate the impact of Ventriculo-Peritoneal Shunt (VPS) on the Health-Related Quality of Life (HRQOL) of children with the infantile hydrocephalus who underwent their first shunt insertion in the first year of life. To compare the outcome of health domains according to sex follow-up period, etiology and shunt valve type (fixed versus programmable pressure).

Methods:

102 children $\leq 1$ years old at the time of new-onset hydrocephalus and shunt insertion. Age-appropriate PedsQL 4.0 versions were completed by the parents or caregivers with the assistance of single neurosurgery resident. Patients were divided into subgroups according to etiology; neural tube defect associated hydrocephalus (NTD-H), intra-ventricular hemorrhage associated with infantile hydrocephalus (IVH-H) and according to the shunt valve type; fixed versus programmable. Statistical analyses were performed using SPSS, IBM version 20. PedsQL 4.0 was presented using mean and standard deviations.

Results:

A decreasing social domain score at $1-3$ years follow up $(n=61)$ compared to 1 year follow up ( $n=41)$ was observed. The two groups did not differ significantly in sex distribution. The mean cognitive score was significantly lower in patients with IVH-H of prematurity compared to NTD-H Better physical and cognitive domains in programmable shunts were compared to fixed pressure type.

\section{Conclusion:}

IVH-H associated with worse cognitive function possibly due to associated brain damage was reported. With long-term follow-up, social function decline probably due to the patients' awareness of their disability was observed. Programmable shunt valve is recommended over fixed type due to the improvement in physical and cognitive functions. Sex of the patients did not affect the outcome.
\end{abstract}

Keywords: Brain, Hydrocephalus, Infants, Outcome, Shunt, Prematurity.

\begin{tabular}{|c|c|c|c|}
\hline Article History & Received: December 08, 2018 & Revised: February 11, 2019 & Accepted: March 06, 201 \\
\hline
\end{tabular}

\section{BACKGROUND}

Hydrocephalus is the most common condition treated by pediatric neurosurgeons [1]. Despite the advent of alternative interventions, Ventriculo-Peritoneal Shunt (VPS) remains the most commonly performed procedure [2]. Endoscopic Third Ventriculostomy (ETV) and Choroid Plexus Cauterization (CPC) showed variable success rate [3]. Shunt valve designed

\footnotetext{
* Address correspondence to this author at the Department of Neurosurgery, Faculty of Medicine, Jordan University of Science and Technology (JUST), Irbid 22110, Jordan; Tel: +962-2-7201000; Fax: +962-2-7095010;

E-mails: heloqayli@yahoo.com,hmeloqayli@just.edu.jo
}

development has improved the success rate especially with shifting from fixed pressure shunt valve system to programmable shunt valves.

Hydrocephalus is predominantly a disease of infants. Infantile hydrocephalus is a complex condition with both genetic and environmental causes. Intraventricular Hemorrhage (IVH) of prematurity is the most common acquired cause, whereas, neural tube defect is the most prevalent congenital etiology [4].

Traditionally, due to the multiplicity of causes and the complexity of the patient population in infantile hydrocephalus, outcome studies of the hydrocephalic patients frequently repor- 
ted a surgical outcome, complications, morbidity and mortality. Consequently, a limited number of studies addressed the issue of young children cognitive, social, emotional and physical outcome [5]. The patients' perceived quality of life and the burden experienced by caregivers are important and should receive more focus.

The Pediatric Quality of Life Inventory (PedsQL 4.0) Generic Core Scales have demonstrated high reported reliability and validity with formats for different pediatric age groups [6]. Multiple language translations are available for PedsQL 4.0 including Arabic validated version [7].

The aim of the present study was to evaluate the HealthRelated Quality of Life (HRQoL) in children who underwent first shunt insertion at the first year of age and to address the differences in the quality of life according to sex, follow-up period (1 year versus 1-3 years), etiology and type of shunt valve. The second goal was to compare HRQoL for the two main subgroups, Neural Tube Defect and Intraventricular Hemor-rhage associated infantile hydrocephalus (NTD-H versus $\mathrm{IVH}-\mathrm{H})$.

\section{METHODS}

\subsection{Patients}

The study population consisted of children $\leq 1$ years old at the time of new-onset hydrocephalus and shunt insertion between the period January 1, 2013, and January 1, 2016. The cohorts were identified by review of the hospital registry IT center based on diagnosis and operative databases. Patients data were collected through a review of hospital electronic medical charts and hospital PACS imaging records. The study was conducted during the period between January and April 2017.

For eligible children, age-appropriate PedsQL 4.0 versions were completed by the parents or caregivers with the assistance of senior neurosurgery resident. For patients aged 2-4 at the time of the study, Arabic version parent report for toddlers (2-4years) PedsQL 4.0 was used, whereas, for patients aged 1-2 years at the time of the study, parents report for infants (age 13-24 months), PedsQL infants scale was used. Consequently, PedsQL infants were considered early, with one year follow up (the form used for data collection of 13-24 months) whereas, for PedsQL toddlers, 1-3 years were considered a longer follow up (the form used for data collection 2-4years).

Patients were included if they met the inclusion criteria: age at the time of shunt insertion $\leq 1$ year. Included patients were divided into three subgroups as described in a study (4). Neural Tube Defect Associated Hydrocephalus (NTD-H);
Intraventricular Hemorrhage associated infantile hydrocephalus (IVH-H); and the third subgroup, Prenatal-Onset Hydrocephalus (PO-H) that was heterogeneous and contained a high propor-tion of congenital malformations so the present study was limited to the more homogenous NTD-H and IVH-H sub-groups.

The following data were recorded for each patient from the electronic medical chart: age at shunt insertion, sex, etiology of hydrocephalus and shunt pressure type fixed versus programmable (patients shifted from one pressure type to another were excluded).

The study was approved by the Ethical Review Board

\subsection{Outcome Measures}

The primary outcome: Pediatric Quality of Life Inventory (PedsQL 4.0), Generic Core Scale validated Arabic appropriate forms were obtained from eprovide. mapi-trust after permission (https://eprovide.mapi-trust.org).

PedsQL infants scale is a Parent report for infants (age 13-24 months) composed of 45 items comprising five dimensions (physical functioning, physical symptoms, emotional functioning, social functioning, and cognitive functioning).

PedsQL 4.0 is a Parent report for toddlers (2-4years) composed of 21 items comprising four dimensions (physical functioning, emotional functioning, social functioning and school functioning)

\section{DATA ANALYSIS}

Statistical analyses were performed using SPSS, IBM version 20. PedsQL 4.0 was presented using mean and standard deviations. Independent-samples t-test was used to compare the means of PedsQL infants and PedsQL 4.0 toddlers parent report scores. The generalized linear mixed model procedure was used to compare the two treatment groups after adjusting for the effects of other variables including age, sex, and smoking. A P-value of less than 0.05 was considered statistically significant.

\section{RESULTS}

A total of 102 patients were included in the present study (excluded were 9 mortalities and 11 patients due to the loss of follow up). Detailed patient characteristics are listed in Table $\mathbf{1 .}$ This included a total of 41 patients who were followed-up for one year (age at data collection 13-24 months) and 61 patients who were followed-up for 1-3 years (age at data collection 24-48 months) after the initial shunt insertion. The two groups did not differ significantly in sex distribution.

Table 1. Shows the relevant characteristics of patients according to period of follow up.

\begin{tabular}{|c|c|c|c|c|c|}
\hline- & \multicolumn{3}{|c|}{ Follow up } \\
\hline- & \multicolumn{2}{|c|}{ 1 year (age 13-24 months) } & \multicolumn{2}{|c|}{ 1-3 years (age 24-48 months) } \\
\hline SEX & - & - & - & - \\
\hline Female & 21 & $51.20 \%$ & 29 & 0.716 \\
\hline Male & 20 & $48.80 \%$ & 32 & - \\
\hline Etiology & - & - & - & $57.50 \%$ & - \\
\hline
\end{tabular}


(Table 1) contd.....

\begin{tabular}{|c|c|c|c|c|c|}
\hline \multirow{3}{*}{$\frac{-}{-}$} & \multicolumn{5}{|c|}{ Follow up } \\
\hline & \multicolumn{2}{|c|}{1 year (age 13-24 months) } & \multicolumn{2}{|c|}{ 1-3 years (age $24-48$ months) } & \multirow{2}{*}{-} \\
\hline & 9 & $22.00 \%$ & 13 & $21.30 \%$ & \\
\hline NTD-H & 25 & $61.00 \%$ & 25 & $41.00 \%$ & - \\
\hline Aqueduct stenosis & 2 & $4.90 \%$ & 6 & $9.80 \%$ & - \\
\hline other causes & 5 & $12.20 \%$ & 17 & $24.60 \%$ & - \\
\hline shunt type & - & - & - & - & 0.328 \\
\hline programmable shunt & 11 & $26.80 \%$ & 22 & $36.10 \%$ & - \\
\hline fixed pressure & 30 & $73.20 \%$ & 39 & $63.90 \%$ & - \\
\hline
\end{tabular}

Table 2. Shows the multivariate analysis of the differences in the quality of life according to sex, follow up period, etiology and type of shunt.

\begin{tabular}{|c|c|c|c|c|c|c|c|c|}
\hline \multirow{2}{*}{-} & \multicolumn{2}{|c|}{ Physical Functioning } & \multicolumn{2}{|c|}{ Emotional Functioning } & \multicolumn{2}{|c|}{ Social Functioning } & \multicolumn{2}{|c|}{ Cognitive Functioning } \\
\hline & Mean & SE & Mean & SE & Mean & SE & Mean & SE \\
\hline Sex & - & - & - & - & - & - & - & - \\
\hline Female & 73.1 & 4.0 & 85.2 & 2.7 & 85.6 & 4.5 & 80.4 & 6.5 \\
\hline Male & 73.5 & 3.5 & 78.7 & 2.4 & 80.4 & 3.9 & 78.7 & 6.3 \\
\hline Follow up (month) & - & - & - & - & - & - & - & - \\
\hline $13-24$ & 74.6 & 4.2 & 82.2 & 2.8 & $88.5^{*}$ & 4.6 & 77.4 & 24.2 \\
\hline$>24-48$ & 72.0 & 3.3 & 81.7 & 2.2 & 77.6 & 3.6 & 81.5 & 27.7 \\
\hline IVH-H & 69.8 & 5.3 & 80.7 & 3.6 & 76.2 & 5.8 & $68.9 *$ & 8.4 \\
\hline NTD-H & 76.5 & 3.9 & 84.5 & 2.7 & 89.7 & 4.3 & 94.7 & 5.4 \\
\hline Others & 73.6 & 4.8 & 80.6 & 3.2 & 83.2 & 5.3 & 75.1 & 10.0 \\
\hline Type of shunt & - & - & - & - & - & - & - & - \\
\hline Programmable shunt & $78.6^{*}$ & 4.3 & 84.8 & 2.9 & 87.2 & 4.8 & $88.7^{*}$ & 8.0 \\
\hline Fixed pressure & 68.0 & 3.3 & 79.0 & 2.2 & 78.8 & 3.6 & 70.5 & 5.1 \\
\hline
\end{tabular}

Statistically significant.

Table 2 shows the multivariate analysis of the differences in the quality of life according to sex, follow-up period, etiology and type of shunt valve. The mean score of physical functioning was significantly higher to that of Programmable shunt indicating better quality of life. None of the variables was significantly associated with emotional functioning. Those who were followed-up at 13-24 months had better social functioning compared to those who were followed-up at 24-48 months.

\section{DISCUSSION}

Functioning of the patient in society and school, community integration, physical and cognitive development compared to peers is of paramount importance that is understood in the pediatric population due to a paucity in standardized evaluation tools and barriers to randomized trials with the small number of patient and a variety of treatment techniques and shunts [8].

The indication for shunt insertion in NTD-H and IVH-H is not standardized in a uniform objective criterion $[9,10]$. In the present study, the diagnosis and surgical indications were based on clinical features, fullness of the anterior fontanel, increasing head circumference, and increasing ventricular width [11]. It has been shown that frequent seizures, longer hospital stay and number of reoperations have been associated with the worse outcome [12], although this was contradicted in other studies [13]. Thus, the present study aimed to find out the effect of sex, etiology, shunt pressure type and follow up period on the quality of life outcome in infantile hydrocephalus.
The value of the current study is that it focuses on the outcome from the patients' perspective (proxy, caregiver) and the unselected nature of patients sample due to the retrospective nature. This may overcome the difficulty with prospective analysis due to the multiplicity of causes and complexity of the patient population.

\section{ETIOLOGY}

Intraventricular hemorrhage (IVH) occurs in approximately $25 \%-30 \%$ of preterm infants. $25 \%-28 \%$ of IVH grade III-IV and $1-4 \%$ of grade I-II develop Post-Hemorrhagic Hydrocephalus (PHH) with $38 \%$ of them having permanent shunts inserted [14]. Whereas, for NTD (associated with Chiari II type malformations and a variety of brain abnormalities), $80 \%-90 \%$ require shunt insertion for hydrocephalus.

The current study shows that the mean cognitive score was significantly lower in patients with IVH of prematurity compared to Chiarri II. This could be related to brain substance damage associated with IVH. Overall, cognitive score tends to be lower than the mean physical score or social-emotional score in both etiology. This is in agreement with previous studies $[15,16]$ that showed learning disabilities, difficulties with narration, oral and reading comprehension in patients with hydrocephalus. The cognitive impairment was shown to increase with the increasing grade of IVH [17].

Moreover, longer-term follow-up showed a lower quality of life in IVH-H compared to congenital types [18]. The cognitive functions of the patients are most important for the 
caregiver burden in older people [19] which may not be the case in younger children.

\section{SHUNT PRESSURE TYPE}

Our study reported better quality of life in programmable shunts compared to fixed pressure type, most significantly in physical and cognitive domains. This could be attributed to the accessibility of shunt pressure adjustment according to patients' changing developmental and clinical progression. Moreover, the non-invasive external pressure adjustment in programmable shunt can encourage physicians to intervene in contrary to surgical intervention needed in the fixed type where neurosurgeons may be hesitant to operate.

\section{LENGTH FOLLOW UP}

The present study represents a short-term follow-up group (1 year) and intermediate follow-up group (1-3 years). There was no difference in the quality of life scores between the two follow-up periods except for lower social domain score with intermediate follow up. This is probably related to the fact that with the increasing age, children become more aware of their problem and the limitations in daily activity compared to their peers. Furthermore, delayed milestones may negatively affect this outcome [13]. This emphasizes the need for support but not overprotection by the caregiver. Long-term follow-up (35 years) has shown similar social function in patients with infantile hydrocephalus compared to a population which might indicate coping with the hydrocephalus over time [19].

\section{CONCLUSION}

Evaluating infantile hydrocephalus with VPS insertion in the first year of life showed that IVH-H associated with the worse functional outcome is possibly due to associated brain damage. Programmable shunt valve is recommended over fixed type due to the improvement in physical and cognitive functions.

\section{LIST OF ABBREVIATIONS}

$$
\begin{array}{ll}
\text { VPS } & \text { Ventriculo-Peritoneal Shunt } \\
\text { NTD-H } & =\text { Neural Tube Defect Associated Hydrocephalus } \\
\text { IVH-H } & = \\
& \text { Intra-Ventricular Hemorrhage Associated Hydro- } \\
\text { cephalus } & \\
\text { PedsQL 4.0 }= & \text { Pediatric Quality of Life Inventory } 4.0 \\
\text { HRQoL } & =\text { Health-Related Quality of Life }
\end{array}
$$

\section{AVAILABILITY OF DATA AND MATERIAL}

The datasets generated and/or analyzed during the current study are not publicly available due to hospital policy but are available from the corresponding author on reasonable request.

\section{AUTHORS CONTRIBUTION}

We declare that all authors have done a substantial contribution to the manuscript. HE and AA designed research. HE conducted research. HE and AA analyzed data and performed statistical analyses. HE, AA wrote the paper. HE had primary responsibility for final content.

\section{ETHICS APPROVAL AND CONSENT TO PARTICIPATE}

The study received ethical approval from the Jordan University of Science and Technology Ethical Committee.

\section{HUMAN AND ANIMAL RIGHTS}

All procedures performed in this study involving human participants were in accordance with the ethical standards of the institutional and/or national research committee and with the 1964 Helsinki declaration and its later amendments or comparable ethical standards.

\section{CONSENT FOR PUBLICATION}

Informed consent was obtained from all parents of the participants.

\section{CONFLICT OF INTEREST}

The authors declare no conflict of interest, financial or otherwise.

\section{FUNDING}

No funding was received for this research. All authors certify that they have no affiliations with or involvement in any organization or entity with any financial interest (such as honoraria; educational grants; participation in speakers' bureaus; membership, employment, consultancies, stock ownership, or other equity interest; and expert testimony or patent-licensing arrangements).

\section{ACKNOWLEDGEMENTS}

Declared none.

\section{REFERENCES}

[1] Baird LC, Mazzola CA, Auguste KI, Klimo P Jr, Flannery AM. Pediatric hydrocephalus systematic review and evidence-based guidelines task force. J Neurosurg Pediatr 2014; 14 (Suppl 1): 35-43.

[2] Yusuf AS, Omokanye HK, Adeleke NA, Akanbi RO, Ajiboye SO, Ibrahim HG. Management and outcome of infantile hydrocephalus in a tertiary health institution in nigeria. J Neurosci Rural Pract 2017; 8(2): 249-53.

[http://dx.doi.org/10.4103/jnrp.jnrp_321_16] [PMID: 28479801]

[3] Kulkarni AV, Riva-Cambrin J, Browd SR, et al. Endoscopic third ventriculostomy and choroid plexus cauterization in infants with hydrocephalus: A retrospective Hydrocephalus Clinical Research Network study. J Neurosurg Pediatr 2014; 14(3): 224-9. [http://dx.doi.org/10.3171/2014.6.PEDS13492] [PMID: 24995823]

[4] Tully HM, Capote RT, Saltzman BS. Maternal and infant factors associated with infancy-onset hydrocephalus in Washington State. Pediatr Neurol 2015; 52(3): 320-5.

[http://dx.doi.org/10.1016/j.pediatrneurol.2014.10.030] [PMID: 255 $42767]$

[5] Hansen D, Vedantam A, Briceño V, Lam SK, Luerssen TG, Jea A. Health-related quality of life outcomes and level of evidence in pediatric neurosurgery. J Neurosurg Pediatr 2016; 18(4): 480-6. [http://dx.doi.org/10.3171/2016.3.PEDS15641] [PMID: 27341609]

[6] Varni JW, Limbers CA, Burwinkle TM. Impaired health-related quality of life in children and adolescents with chronic conditions: A comparative analysis of 10 disease clusters and 33 disease categories/severities utilizing the PedsQL 4.0 Generic Core Scales. Health Qual Life Outcomes 2007; 5: 43. [http://dx.doi.org/10.1186/1477-7525-5-43] [PMID: 17634123]

[7] Arabiat D, Elliott B, Draper P, Al Jabery M. Cross-cultural validation of the Pediatric Quality of Life Inventory ${ }^{\mathrm{TM}} 4.0$ (PedsQL ${ }^{\mathrm{TM}}$ ) generic core scale into Arabic language. Scand J Caring Sci 2011; 25(4): 828-33. 
[http://dx.doi.org/10.1111/j.1471-6712.2011.00889.x] [PMID: 215641 51]

[8] Vinchon M, Rekate H, Kulkarni AV. Pediatric hydrocephalus outcomes: A review. Fluids Barriers CNS 2012; 9(1): 18.

[http://dx.doi.org/10.1186/2045-8118-9-18] [PMID: 22925451]

[9] Papile LA, Burstein J, Burstein R, Koffler H. Incidence and evolution of subependymal and intraventricular hemorrhage: A study of infants with birth weights less than 1,500 gm. J Pediatr 1978; 92(4): 529-34. [http://dx.doi.org/10.1016/S0022-3476(78)80282-0] [PMID: 305471]

[10] Adams-Chapman I, Hansen NI, Stoll BJ, Higgins R. Neurodevelopmental outcome of extremely low birth weight infants with posthemorrhagic hydrocephalus requiring shunt insertion. Pedia-trics 2008; 121(5): e1167-77.

[http://dx.doi.org/10.1542/peds.2007-0423] [PMID: 18390958]

[11] Volpe JJ. Neurology of the Newborn. $4^{\text {th }}$ ed. Philadelphia, PA: WB Saunders 2001; pp. 403-53.

[12] Kulkarni AV, Shams I. Quality of life in children with hydrocephalus: Results from the Hospital for Sick Children, Toronto. J Neurosurg 2007; 107(5)(Suppl.): 358-64.

[PMID: 18459898]

[13] Khan SA, Khan MF, Bakhshi SK, et al. World neurosurg quality of life in individuals surgically treated for congenital hydrocephalus during infancy: A single-institution experience 2017; 101: 247-53.

[14] Christian EA, Jin DL, Attenello F, et al. Trends in hospitalization of preterm infants with intraventricular hemorrhage and hydrocephalus in the United States, 2000-2010. J Neurosurg Pediatr 2016; 17(3): 260-9. [http://dx.doi.org/10.3171/2015.7.PEDS15140] [PMID: 26544084]

[15] Hoppe-Hirsch E, Laroussinie F, Brunet L, et al. Late outcome of the surgical treatment of hydrocephalus. Child Nerv Syst 1998; 14(3): 97-9.

[http://dx.doi.org/10.1007/s003810050186] [PMID: 9579862]

[16] Lindquist B, Carlsson G, Persson EK, Uvebrant P. Learning disabilities in a population-based group of children with hydrocephalus. Acta Paediatr 2005; 94(7): 878-83.

[http://dx.doi.org/10.1080/08035250510027345] [PMID: 16188809]

[17] Radic JA, Vincer M, McNeely PD. Outcomes of intraventricular hemorrhage and posthemorrhagic hydrocephalus in a population-based cohort of very preterm infants born to residents of Nova Scotia from 1993 to 2010. J Neurosurg Pediatr 2015; 15(6): 580-8.

[http://dx.doi.org/10.3171/2014.11.PEDS14364] [PMID: 26030329]

[18] Kazui H, Mori E, Hashimoto M, Ishikawa M, Hirono N, Takeda M. Effect of shunt operation on idiopathic normal pressure hydrocephalus patients in reducing caregiver burden: Evidence from SINPHONI. Dement Geriatr Cogn Disord 2011; 31(5): 363-70.

[http://dx.doi.org/10.1159/000328625] [PMID: 21625136]

[19] Kutscher A, Nestler U, Bernhard MK, et al. Adult long-term healthrelated quality of life of congenital hydrocephalus patients. J Neurosurg Pediatr 2015; 16(6): 621-5. [http://dx.doi.org/10.3171/2015.4.PEDS15106] [PMID: 26339956]

(C) 2019 Eloqayli and Alyousef.

This is an open access article distributed under the terms of the Creative Commons Attribution 4.0 International Public License (CC-BY 4.0), a copy of which is available at: https://creativecommons.org/licenses/by/4.0/legalcode. This license permits unrestricted use, distribution, and reproduction in any medium, provided the original author and source are credited. 